\title{
Implications of the Right to Science for People with Disabilities
}

\author{
Valerie J. Bradley
}

This chapter will explore the unique and critical importance of the right to science for people with intellectual, physical, and mental health disabilities. To put the subject in a global context, approximately one billion people, or 15 percent of the world's population, experience some form of disability, and disability prevalence is higher for developing countries. One-fifth of the global total, or between 110 million and 190 million people, experience significant disabilities (The World Bank, 2019). Science and the products of science are critical to the realization of the human rights of people with disabilities and to their inclusion in society. This is especially true in the time of the corona virus pandemic which has presented additional challenges for people with disabilities over and above those visited on the general population.

The right to science, this chapter will suggest, is a powerful tool to support and inform other rights as they relate to people with disabilities. In an age dominated by fast-paced technological advances, the right to science represents a meaningful way to protect the relationship between the scientific community and people with disabilities. It is vital that people with disabilities are not excluded from decisions about scientific priorities, the conduct of scientific research, and the design of technology that will impact their lives. Diversity in the development of new technology such as algorithms, for example, is essential in order to reflect the characteristics of those people who will ultimately be governed and affected by them. For example, informed consent policies for people with intellectual disabilities are required in order to ensure that they are neither exploited nor excluded from scientific studies.

The ensuing discussion in this chapter will include the history of the disability rights movement, the ways in which the Convention on the Rights of Persons With Disabilities reaffirms the right to science, the role of science in the lives of people with disabilities - both positive and negative, the importance of scientifically based treatment interventions, the importance of including people with disabilities in scientific research and the ability of people with disabilities to gain access to scientific findings. It will conclude with some recommendations for a more 
inclusive approach that embraces the views and needs of people with disabilities in the scientific enterprise, including access to science as part of international monitoring of the CRPD by the Special Rapporteur and the Committee on the Rights of People with Disabilities.

\subsection{HISTORY OF THE DISABILITY RIGHTS MOVEMENT}

The 196os are remembered as a period of disruption. This disruption took the form of social protest against racial segregation, authoritarianism, colonialism, discrimination against women, and an unpopular war. In the United States, this period also saw the mobilization of people with disabilities and their families. In the mental health field, consumer groups like the Mental Patients Liberation Front took on involuntary treatment and forced medication. They argued for housing, jobs, and income supports in addition to psychiatric services (Chamberlin, 1990). In the developmental disabilities field, the fledgling Association for Retarded Children (now The Arc) organized families around the country to advocate for a more positive public perception of children with intellectual disabilities and their potential (The Arc, n.d.). They sought concrete reforms such as access to education, preschool, and jobs. In the physical disability community, important figures such as Ed Roberts one of the founders of the historic Berkeley Center for Independent Living in 1972 rallied people with physical disabilities to take charge of their own lives, to demand the support they needed to live independently, and to reject the medical model and the notion that they needed to be fixed (Anderson, 2013). Finally, activism among the elderly also burgeoned during this period, as groups like the Gray Panthers argued against forced retirement and in favor of better health care, housing, and income support (Sanjek, 2009).

The emergence of advocacy for the human and legal rights of people with disabilities was not limited to the USA. Similar movements were taking place around the world as people with disabilities and family members advocated access to education, income support, employment, and inclusion in their communities. In 1969 , a group of parent-sponsored organizations from around the world formed The International League of Societies for the Mentally Handicapped (Dybwad, 1975). The group would later become known as Inclusion International. Subsequently, multiple groups representing specific disability organizations formed in multiple countries, but it wasn't until 1999 that an international pan-disability alliance was forged - The International Disability Alliance (International Disability Alliance, "Who We Are"). The Alliance brought together a global network of previously separate disability organizations under one umbrella. Some of the groups that joined forces were the World Blind Union, the World Federation of the Deaf, the World Network of Users and Survivors of Psychiatry, and the International Federation of Hard of Hearing People. Regional networks such as the Arab Organization of People with Disabilities and the Latin American Disabled Persons Organization were 
included in 2007 , as well as regional organizations of persons with disabilities and their families.

The IDA was instrumental in establishing the International Disability Caucus (IDC) which was comprised of global, regional, and national organizations of persons with disabilities and allied non-governmental organizations (NGOs). The IDC became a critical player in negotiations regarding the provisions of the United Nations Convention on the Rights of Persons with Disabilities (CRPD) (UN General Assembly, 2007)).

According to an interview with Diana Samarasan of the Disability Rights Fund (Bell, 2014), the negotiations that preceded the passage of the CRPD were unique in that one-third of the seats in the working group that drafted the treaty were reserved for people with disabilities. Samarasan stressed that the process brought together people with disabilities from around the world and from different disability organizations including blind people, people with intellectual disabilities, people with psychosocial disabilities, people with physical disabilities, and little people. For the first time, they had a platform and a target for joint advocacy. The IDA now has a secretariat in New York and in Geneva. In addition to monitoring state compliance with the CRPD, the IDA is involved with all of the UN development organizations for inclusion of people of disabilities.

\subsection{RIGHT TO SCIENCE AND THE CONVENTION ON THE RIGHTS OF PERSONS WITH DISABILITIES}

\subsubsection{Background of the Right to Science}

The human rights of people with disabilities articulated in the Convention on the Rights of People with Disabilities directly connect to the principles and aspirations of another right grounded in affirmation of global human rights - the Right to Science (hereafter RtS). The RtS posits generally that all citizens have a human right to enjoy the benefits of scientific progress. The right can be traced to Article 27 of the United Nations 1948 Universal Declaration of Human Rights, which was adopted in the wake of the human carnage that resulted from World War II. In 1966, the UN adopted the International Covenant on Economic, Social and Cultural Rights which codified the provisions of the Declaration under international law. Article 15(1) of the Covenant states that:The States Parties to the present Covenant recognize the right of everyone:

(a) To take part in cultural life;

(b) To enjoy the benefits of scientific progress and its applications;

(c) To benefit from the protection of the moral and material interests resulting from any scientific, literary or artistic production of which he is the author. 
According to Porsdam-Mann, et al., (2018), who conducted a methodical review of the scholarship on the RtS, the right has not received the attention needed to make it a force for scientific freedom, access, policy reform, and improvement of human rights. In order to elevate the RtS, it will be necessary for the scientific community as well as those who benefit from the fruits of scientific research to find ways of promoting the right. One of the communities with a direct interest in RtS is people with disabilities and their families.

\subsubsection{Provisions of the CRPD}

The Convention on the Rights of People with Disabilities asserted a broad range of rights and obligations on States consistent with the aspirations of the international disability rights movement. The provisions went well beyond traditional medical and clinical concerns to embrace the multiple aspects of a quality and valued life. That included the right to live a full life in the community. The CRPD definition of the beneficiaries of the provisions, stated in Article 1, is as follows: "People with disabilities include those who have long-term physical, mental, intellectual or sensory impairments which in interaction with various barriers may hinder their full and effective participation in society on an equal basis with others."

Prior to the CRPD, there were other declarations on the rights of people with disabilities, but they were not binding on States. During 1981, the International Year of Disabled Persons, there were activities geared towards bringing attention to the rights of people with disabilities including conferences, research projects, and policy initiatives. This included the First Founding Congress of Disabled People International, in Singapore from November 30 to December 6. In 1982, the UN General Assembly took a major step towards ensuring effective follow-up to the International Year by adopting, on December 3, 1982, the World Programme of Action concerning Disabled Persons. The Programme restructured disability policy into three distinct areas: prevention, rehabilitation, and equalization of opportunities.

The 199os were deemed the Decade of Disabled People. In recognition of this, the United Nations passed Standard Rules on the Equalization of Opportunities for Persons with Disabilities in 1993. The twenty-two rules were arranged in four chapters - preconditions for equal participation, target areas for equal participation, implementation measures, and the monitoring mechanism - and cover all aspects of life of persons with disabilities.

The CRPD was an important advance on previous initiatives since it required compliance on the part of signatories. Unlike previous initiatives, the CRPD was both a development and human rights instrument as well as a policy instrument that was cross-disability and cross-sectoral. The UN convention has now been signed by 164 countries worldwide and ratified by 180; 94 countries have signed the Optional 
Protocol to the Convention, and 95 have ratified it. It is therefore legally binding on those states who have ratified it.

The CRPD has taken on even more relevance during the coronavirus pandemic. The Council of Europe (2020) has noted:

Although the ongoing crisis is unprecedented, respect for international human rights standards must be at the heart of state responses to it. In this connection, it is important to remember that Article 11 of the UN Convention on the Rights of Persons with Disabilities (CRPD), ratified by 46 of the 47 member states of the Council of Europe, provides that states shall take "all necessary measures to ensure the protection and safety of persons with disabilities in situations of risk, including situations of armed conflict, humanitarian emergencies and the occurrence of natural disasters."

The specific protections outlined above and the antidiscrimination provisions of the CRPD are particularly important during a pandemic given threats to the accessibility of needed supports concern as well among persons with disabilities and their advocates that they will be left behind in accessing lifesaving medical interventions.

\subsubsection{Implications of the CRPD for the Right to Science}

The Convention marks a "paradigm shift" in attitudes and approaches to persons with disabilities. Persons with disabilities are not viewed as "objects" of charity, medical treatment, or social protection; rather as "subjects" with rights, who are capable of claiming those rights and making decisions for their own lives based on their free and informed consent as well as being active members of society (United Nations. Convention on the Rights of Persons with Disabilities and Its Optional Protocol (PPT) (UN CRPD PPT)).The author argues that for people with disabilities to realize the expansive rights laid out in the CRPD they must rely heavily on the availability of both the products of scientific inquiry as well as scientific research that generates evidence-based practices and policies that lay out successful intervention strategies. Some of the technological and other innovations that have made it possible for individuals to live in communities, to be educated, to be employed, to communicate, and to generally lead lives of meaning include ("What Are Some Types of Assistive Devices" n.d.):

- GPS technology that assists people navigate their environment;

- Augmentative and alternative communication devices;

- Computer software and hardware, such as voice recognition programs, screen readers, and screen enlargement applications, to help people with mobility and sensory impairments use computers and mobile devices;

- Adaptive equipment for a range of functions including eating, bathing, etc.

- Remote monitoring by direct support professionals in order to augment staff; 
- Tools such as automatic page turners, book holders, and adapted pencil grips to help children with disabilities to participate in educational activities;

- Smart homes that can control lighting, climate, entertainment systems, appliances, and security and alarm systems;

- Universal architectural design;

- Health monitoring and health aids and prompts;

- Adapted cell phones;

- Mobility aids (electric wheelchairs, prosthetic devices, etc.);

- Hearing aids;

- Cognitive aids, including computer or electrical assistive devices, to help people with memory, attention, or other challenges in their thinking skills.

\section{RIGHTS IN THE CRPD}

- Right to life, liberty and security of the person

- Equal recognition before the law and legal capacity

- Freedom from torture

- Freedom from exploitation, violence and abuse

- Right to respect physical and mental integrity

- Freedom of movement and nationality

- Right to live in the community

- Respect for privacy

- Respect for home and the family

- Right to education

- Right to health

- Right to work

- Right to adequate standard of living

- Right to participate in political and public life

- Right to participation in cultural life

- Freedom of expression and opinion

In addition to these assistive technologies, there are also rehabilitation technologies that aid people with other than congenital disabilities including ("What Are Some Types of Rehabilitation Technologies," n.d.):

- Specialized robots help people regain and improve function in arms or legs after a stroke.

- Virtual reality allows people recovering from injury to retrain themselves to perform motions within a virtual environment.

- Musculoskeletal modeling and simulations can help improve assistive aids or physical therapies. 
- Transcranial magnetic stimulation (TMS) helps people who have had a stroke recover movement and brain function.

- Transcranial direct current stimulation helps patients to recover movement following a stroke or other conditions.

- Analysis of human motion to gives a detailed picture of a person's specific movement challenges to guide proper therapy.

The global importance of access to technology for people with disabilities internationally was memorialized at the 71st World Health Assembly (WHA, 2018) during which the Resolution on Improving Access to Assistive Technology was unanimously approved. The Resolution calls on Member States to develop, implement, and strengthen policies and programs to improve access to assistive technology (AT) within universal health coverage. The Resolution was sponsored by Pakistan and requires the World Health Organization (WHO) to prepare a global report by 2021 on access to AT in Member States. The Resolution makes specific mention of the Convention on the Rights of Persons with Disabilities as well as the 2030 Agenda for Sustainable Development as actions taken internationally that underpin and provide a rationale for AT access.

The resolution also recognizes the need to support the application of technology with trained personnel to ensure maintenance, and quality and safety. In addition, it requires Member states to develop national lists of priority products, to carry out research, to develop new products, and to invest in barrier-free environments so that all people who need assistive technology can make optimum use of it.

The provisions of the CRPD, when combined with the human right to science and the move to establish a right to technology - provide a road map for understanding the ways in which the right can guarantee access to the technology and other scientific advances needed to support an enhanced quality of life for people with disabilities. In other words, taken together, the CRPD and the right science provide both the aspiration and the means for achieving lives of equality and inclusion.

\subsection{EVIDENCE-BASED PRACTICES}

In order to ensure that the treatments, therapies, rehabilitation techniques, technologies, and other interventions applied to maintain or improve functioning of individuals with disabilities are efficacious, scientific proof of such efficacy is considered the gold standard. Evidence is defined as (Singer, Agran, and Spooner, 2017, page 63):

formal objectivist research that uses experimental control to make a case for a causal or functional relation between a practice and its outcomes, that is, to rule out plausible alternative explanations. It is this ruling out of plausible alternatives that is central to the requirement that evidence be drawn from controlled experiments (e.g., randomized control trials, single-case research. 
Without the use of evidence to validate such interventions, people with disabilities have been subjected to approaches that are the product of poor science, fads, or wishful thinking and that have ultimately proven to be inefficacious. In some instances, the interventions have continued even after the evidence has proved their inefficaciousness conclusively.

Singer, et al. (2017) assert that the pursuit of unproven practices is the result of "the absence of well-established evidence and an effective interface between scientific researchers and family members and practitioners" (page 67). Examples of the persistence of practices proven over and over not to result in the presumed outcome include Facilitated Communication (FC). According to a review of research on FC, it does not elicit speech from those who previously did not use words to speak via a typing device (American Psychological Association, 2003). The Autism Science Foundation (2019) has denounced a range of unproven treatments for autism including chelation therapy, nutritional supplements, hyperbaric oxygen therapy, secretin injections, and nicotine patch therapy. Patterning is a series of exercises designed to improve the "neurologic organization" of a child's neurologic impairments and has been used on children with cerebral palsy, Down Syndrome, learning disabilities, and brain injuries. The treatment, according to the American Academy of Pediatrics (1999), is based on an outmoded and oversimplified theory of brain development. Research does not support the claims by proponents that this treatment is efficacious, and its continued use is unwarranted. All of these approaches, though discredited and wasteful, have advocates to this day. While these advocates by and large operate with the best of intentions, they are depriving people with disabilities and their families of the scientific research needed to help them make informed decisions.

\subsection{PEOPLE WITH DISABILITIES AS UNWITTING SCIENTIFIC SUBJECTS}

The use of unproven treatment interventions on people with disabilities seems benign when compared to the multiple instances over decades of people with disabilities being included in scientific experimentation without their knowledge. For instance, in 1949, at Fernald State School (previously the Massachusetts School for the Feeble Minded), seventy-four boys aged ten to seventeen were recruited to join the "Science Club." They were given special privileges but were also given oatmeal for breakfast with milk laced with radiative tracers. While health dangers were ultimately determined to be minimal (small increase in cancer risk), neither the residents nor their families were given the opportunity to make an informed decision. In another experiment, some of the boys were injected with radioactive calcium. These experiments were approved by the Atomic Energy Commission. Ironically, some of the boys enthusiastically joined the club thinking that the scientists themselves would expose the abuse that went on at the facility (Boissoneault, 2017). 
Additional examples of unwitting victims of experimentation were described in an NBC health posting by Associated Press journalist Mike Stobbe (2011). He described one study that began in 1942 that targeted male subjects who were residents of a state mental hospital in Ypsilanti, Michigan. The study involved injecting the men with an experimental flu vaccine and then exposing them to the flu months later. One of the co-authors was Dr. Jonas Salk who later discovered the polio vaccine. Given their disabilities and lack of cognitive acuity, it was not clear that any of them understood what was being done to them. Stobbe also described a second federally funded study in the 1940s that exposed men from mental hospitals in Middletown and Norwich Connecticut to hepatitis. The scientist was Dr. W. Paul Havens Jr. who was a World Health Organization expert on viral diseases.

Finally, Eric Boodman writing for Stat (2015) described an experiment at a Staten Island School for students with intellectual disabilities. The study, which took place from 1963 to 1966 involved feeding the children human feces in milkshakes. The chief scientist argued that he obtained consent from families, but it was not clear whether the families understood what the experiment involved. The experiment eventually led to the discovery that there were at least two types of hepatitis - Type $\mathrm{A}$ and Type B.

Scientists involved in these and other studies that took advantage of vulnerable and cognitively compromised individuals argued that the experiments befitted the greater good. For people with disabilities, the RtS should include an assumption that scientific progress is not achieved at the expense of their human rights such as the right to be free from exploitation, the right to health, and the right to life, liberty, and security.

\subsection{PEOPLE WITH DISABILITIES AS PARTICIPANTS IN SCIENTIFIC RESEARCH}

With the slogan, "Nothing About Us Without Us," people with disabilities have increasingly pressed to be included in discussions about research topics and research methods, and to be included a participant in scientific research projects. This kind of involvement has been described as "participant action research" (PAR). This approach is not limited to people with disabilities but has currency with a range of marginalized groups including minorities, indigenous peoples, and LGBTQ+ communities. With respect to PAR for people with disabilities, Balcazar, Keys, Kaplan and Suarez Balcazar (2006) noted four characteristics of this research approach (page 1): (1) the active role individuals with disabilities to define, analyze, and solve identified problems; (2) the opportunities for more accurate and authentic analysis of the social reality of people with disabilities; (3) the resulting awareness among people with disabilities about their own resources and strengths; and (4) the opportunities for improving the quality of life of people with disabilities. Stack and MacDonald (2014), following their review of the PAR literature in developmental 
disabilities, concluded that: "action research with adults with developmental disabilities holds promise for people with developmental disabilities, their allies within and outside the research, community, and a more inclusive society" (page 90).

The Autism community has been particularly aggressive in advocating for inclusion in research efforts specifically aimed at people on the spectrum. They argue that research has traditionally focused on causes or cures for autism and have primarily targeted children, not adults; and men, to the exclusion of women. An analysis of the 2010 National Institutes of Health autism research agenda found that of \$217 million devoted to autism research in that year, only 1.5 percent of the funds went towards research on the needs of autistic adults while only 2.45 percent went towards research on the service-needs of people on the autism spectrum across the lifespan (Autism Self Advocacy Network, 2012; Office of Autism Research Coordination IACC Portfolio Analysis Web Tool, 2012). The Autistic Self-Advocacy Network has argued that people with autism should be included in determining research priorities in order to ensure that topics of concern to the community are addressed including communication strategies, building relationships, employment support, and strategies to manage their support and services.

In addition to the importance of involving people with disabilities in determining research priorities that affect their lives, it is also important to ensure the people with disabilities are included as subjects in longitudinal health and drug trials. People with disabilities have historically been left out of such studies. Without their participation, the results of these important studies will not include important information about any idiosyncratic disease markers and drug interactions affecting people with disabilities. Maya Satabello (2018) makes the case that such inclusion is of particular importance to the growing field of precision medicine that involves treatment initiatives that target the particular genome of individuals or groups of individuals relative to specific health conditions. She makes that point that if people with disabilities are not intentionally included, any scientific advances may be limited and health disparities for this population will be exacerbated.

\subsection{BIG DATA AND ARTIFICIAL INTELLIGENCE DIGITAL DIVIDE}

\subsubsection{Big Data Applications}

Big data, or extremely large data sets that may be analyzed to reveal patterns, trends, and associations, especially relating to human behavior and interactions, can be a substantial boon to people with disabilities. In a recent blog by the Data-Pop Alliance (2016) seven areas of research in which big data could be employed to ameliorate specific challenges that they face:

- Voting and Representation - including whether people with disabilities are under-represented of disenfranchised; 
- Employment - mapping the availability and location of employment opportunities, monitoring compliance with employment mandates, or assessing the variable that predict employment success;

- Community and Social Media - studying people with disabilities as a network with specific characteristics, using social media to gain access to others with similar challenges, medical issues;

- Accessibility - using data, including crowd-sourcing, to map locations of public places, businesses, lodging, and transportation that are accessible as well as a tool determine compliance with accessibility standards;

- National and International Programs - comparing countries based on their implementation of national and global targets, such as the CRPD;

- Education - There are a variety of descriptive uses of data, in particular relating to the proportion of children with disabilities who are included in the education system (either in specially designed programs or integrated into other programs), to observing what opportunities exist for them to receive education and identifying gaps and issues in the education system. Data can also be used for creating education material, such as using innovative approaches to digitize books or studying the effectiveness of various teaching tools and methods;

- Awareness and Advocacy - using big data on the topics above to raise awareness, to monitor progress toward global goals, and to influence disability policy reform.

With respect to using big data to monitor international progress, The Internet Governance Lab recently co-sponsored "Data, Disability and Development: Innovative Approaches to Monitoring and Evaluating CRPD Implementation and Disability-Inclusive Development using Big Data Analytics and Text Mining." This session took place at the 11th Conference of States Parties to the UN Convention on the Rights of Persons with Disabilities (CRPD) at the United Nations in New York, in 2018. Topics included international mapping of accessibility to political life, using smartphone and online applications to crowd-source data on accessibility to cities, and development a categorization model to automate the analysis of CRPD state party reports.

Big data can also pose challenges to people with disabilities. Specifically, many of the data sets used to develop a range of technologies, medical interventions, or to assess or evaluate quality of life and well-being of the general population, fail to include data from or regarding people with disabilities. Reasons for the absence of such data includes lack of access to people with disabilities, privacy concerns, communication issues, and lack of knowledge regarding the value this data can provide. Without representation in these data sets, the specific needs and rights of individuals with disabilities will be overlooked, or worse, directly contravened.

Sharona Hoffmann (2017) argues that big data may lead to employment discrimination in respect of people with disabilities. She argues that the Americans with 
Disabilities Act (ADA) should be amended in response to the big data phenomenon "in order to protect individuals who are perceived as likely to develop physical or mental impairments in the future" (page 777). She suggests that employers can obtain medical data about employees not only through the traditional means of medical examinations and inquiries, but also through the nontraditional mechanisms of social media, wellness programs, and data brokers. "Information about workers' habits, behaviors, or attributes . . . can be used to create profiles of undesirable employees ... to exclude healthy and qualified individuals" whose profiles suggest that they may be vulnerable to future disabilities or illnesses. Her argument could also extend to screening for insurance eligibility or bank loans if such screening shows certain markers for disease and disability as revealed through big data.

\subsubsection{Artificial Intelligence}

Like big data, artificial intelligence and machine learning promise enormous benefits for people with disabilities whether through GPS tracking, voice recognition, or products like digital personal assistants such as Alexa that can remotely control a range of household functions (e.g., lights, music, alarms, etc.). However, the algorithms that drive the machine learning behind such devices do not routinely include data on people with disabilities. As a consequence, voice recognition devices may not recognize deaf speakers, people with cerebral palsy, or people with cognitive limitations. Facial recognition programs may not recognize people with Down Syndrome or facial dysplasia. Trewin (2018), who is an accessibility analyst for IBM, argues that unless the data that underpins the algorithms behind elements of AI such as facial, speech, and gesture recognition, they will not be accessible to those left out of the data. There are several reasons why this data is not included in such algorithms including privacy concerns, legal restrictions, and lack of accessibility to accurate data. The possible discrimination that these algorithms may visit on a range of marginalized and disadvantaged groups is a growing and complicated issue and cannot be thoroughly examined here. However, suffice it to say that, as Trewin (2018, pages 6-7) asserts: "For systems that will make or influence decisions affecting human lives, it is critical that a broad range of user stakeholders are involved in development, including people with disabilities who can help developers to think through the possible implications of the technology, and to test the technology's performance on edge cases and under-represented populations."

\subsubsection{Digital Divide}

Being able to navigate the Internet is facilitated by a variety of devices including computers, tablets, and smart phones and is increasingly becoming critical to 
modern life. Being a part of social media, shopping, communicating with friends, getting directions, and ordering food are all increasingly being done online. However, a recent Pew poll conducted in 2016 (Anderson and Perrin, 2017), Americans with disabilities were about three times as likely as those without a disability to say they never go online (23 percent versus 8 percent). Further, adults with disabilities are roughly 20 percentage points less likely to say they subscribe to home broadband and own a traditional computer, a smartphone, or a tablet.

The survey also found that people with disabilities have fewer devices capable of connecting with the Internet. One-in-four respondents said they had high-speed Internet at home, a smartphone, a desktop or laptop computer and a tablet, compared with 42 percent of those who report not having a disability. For those able to get onto the Internet, respondents with disabilities said they spent less time connected than their nondisabled peers. Finally, people with disabilities indicated that they had less confidence in their ability to negotiate the Internet.

Unfortunately, many assistive technologies can be expensive. Screen readers, text-to-speech software, and Augmentative and Alternative Communication (AAC) devices can all cost more than $\$ 1,000$ each, and not everyone knows how to find grants in their countries to secure such devices. These factors have prevented many people with disabilities from gaining access to technological advancements, leaving only a select population with the ability to take advantage of them. Digital exclusion "means fewer employment, educational, social and political opportunities, lack of access to confidential financial and health information, and a general inability to fully participate in all aspects of society" (Feingold, 2013, paragraph 3) Advocates for people with disabilities argue that digital inclusion is a civil right.

\section{$9 \cdot 7$ CONCLUSiON}

This discussion of the application of the right to science to people with disabilities is not meant to be exhaustive but hopefully highlights the complexity and interrelationship of the issues involved. Science and the products of science are critical to the realization of the human rights of people with disabilities and to their inclusion in society. However, the conduct of science also poses challenges and obstacles to people with disabilities when they are excluded from decisions about scientific priorities, the conduct of scientific research, and the design of technology. The following are some brief recommendations aimed at increasing awareness in the general public and the scientific community regarding the needs and aspirations of a critical segment of the global population:

- Introduce disability issues into engineering and other curricula to ensure that product development includes access considerations. 
- Include people with disabilities in design decisions for products, equipment, clinical approaches and other scientific endeavors that will affect their inclusion in their communities and their ability to manage their own lives.

- Support evidence-based practices normed on disability populations.

- Include people with disabilities in data used to identify markers for specific illnesses.

- Explore informed consent policies for people with intellectual disabilities in order to ensure that they are neither exploited nor excluded from scientific studies.

- In developing nations with few resources, prioritize low cost solutions.

- Include access to science as part of international monitoring of the CRPD by the Special Rapporteur and the Committee on the Rights of People with Disabilities.

- Develop longitudinal surveys to track the well-being of people with disabilities and to identify gaps in their access to science-based supports.

\section{REFERENCES}

American Academy of Pediatrics, Committee on Children with Disabilities. (1999). The Treatment of Neurologically Impaired Children Using Patterning. www.srmhp.org/arch ives/patterning.html.

American Psychological Association. (2003). Facilitated Communication: Sifting the Psychological Wheat from the Chaff. www.apa.org/research/action/facilitated.

Anderson, A. (2013). Ed Roberts: The father of independent living. Retrieved from www .foundsf.org/index.php?title=Ed_Roberts:_The_Father_of_Independent_Living.

Anderson, M. and Perrin, A. (2017). Disabled Americans are less likely to use technology. Pew Research Center. d.docs.live.net/6274dzedic7ocbeb/Desktop/Integra/Porsdam/normalised $\%$ zoms\%zofiles-for\%zocopyediting/www.pewresearch.org/fact-tank/2017/04/o7/disabledamericans-are-less-likely-to-use-technology.

Autism Science Foundation (2019). Beware of non-evidence-based treatment. https://autisms ciencefoundation.org/what-is-autism/beware-of-non-evidence-based-treatments/nts.

Autistic Self-Advocacy Network (2012). Update on November 29 Autism Hearing. https:// autisticadvocacy.org/2012/11/updated-statement-on-november-29-autism-hearing/.

Balcazar, F. E., Keys, C. B., Kaplan, D. L., and Suarez Balcazar, Y. (2006). Participatory action research and people with disabilities: Principles and challenges. Canadian Journal of Rehabilitation, Winter, 1998, Vol.12(2), 105-112.

Bell, B. (2014). The global disability rights movement: Winning power, participation, and access. Huffington Post www.huffpost.com/entry/the-global-disability-rig_b_5651235.

Boissoneault, L. (2017). A spoonful of sugar helps the radioactive oatmeal go down: When MIT and Quaker Oats paired up to conduct experiments on unsuspecting young boys. Smithsonian.com. d.docs.live.net/6274dzedic7ocbeb/Desktop/Integra/Porsdam/normal ised\%zoms\% zofiles-for\%zocopyediting/www.smithsonianmag.com/history/spoonful-sugarhelps-radioactive-oatmeal-go-down-180962424.

Chamberlin, J. (1990). The ex-patients' movement: Where we've been and where we're going. The Journal of Mind and Behavior, Vol. 11(3), 323-336. 
Council of Europe. (2020). Persons with disabilities must not be left behind in the response to the COVID -19 pandemic. www.coe.int/en/web/commissioner/-/persons-with-disabilitiesmust-not-be-left-behind-in-the-response-to-the-covid-19-pandemic.

Data-Pop Alliance DataFeed (2016). Big Data and Disability: Part 1. https://datapopalliance .org/big-data-and-disability-part-1/.

Dybwad, R. F. (1975). Mental handicap: The world scene. Disability History Museum. https:// disabilitymuseum.org/dhm/lib/detail.html?id=2010\&\&print=1\&page=all.

Feingold, L. (2013). The digital divide and people with disabilities. www.lflegal.com/2013/08/ digital-divide/.

Hoffman, S. (2017). Big data and the Americans with Disabilities Act. 68 Hastings Law Journal 777; Case Legal Studies Research Paper No. 2016-33. Available at SSRN: https://ssrn.com labstract $=2841431$.

International Society for Orthotics and Prosthetics. (2018). Resolution to improve access to assistive technology adopted at World Health Assembly. www.ispoint.org/news/405719/ Resolution-to-improve-access-to-assistive-technology-adopted-at-World-Health-Assembly.htm.

Internet Governance Lab. (2018). Data, disability and development: innovative approaches to monitoring and evaluating CRPD implementation and disability-inclusive development using big data analytics and text mining. https://internetgovernancelab.org/events/cosp-11side-event.

Office of Autism Research Coordination. (2012). IACC Portfolio Analysis Web Tool. Retrieved from: https://iacc.hhs.gov/apps/portfolio-analysis-web-tool/funderdata? funderId=4010\&fy=2010.

Porsdam Mann, S., Donders, Y., Mitchell, C., Bradley, V. J., Choug, M. F., M. Mann, Church, G., and Porsdam, H., (2018). Advocating for science progress as a human right. Proceeding of the National Academy of Sciences of the United States. https://www.pnas.org /content/115/43/10820.

Sabatello, M. (2018). Precision medicine, health disparities, and ethics: The case for disability inclusion. Commentary. Genetics in Medicine. Vol. 2(4), 397-399.

Sabatello, M., and Schulze, M. (2013). Human Rights and Disability Advocacy. Philadelphia: University of Pennsylvania Press. muse.jhu.edu/book/27609.

Sanjek, R. (2009). Gray Panthers. Philadelphia, PA: University of Pennsylvania Press.

Singer, H. S., Agran, Martin, and Spooner, Fred (2017). Evidence-Based and Values-Based Practices for People With Severe Disabilities. Research and Practice for Persons with Severe Disabilities. Vol. 42 (1), 62-72. http://web.a.ebscohost.com.ezp-prodi.hul.harvard.edu /ehost/pdfviewer/pdfviewer?vid=1\&sid=40353ce4-2599-4fa4-aeo9-ce8b3a29520b\% 40sessionmgr4007.

Stack,E. and McDonald, K. E. (2014). Nothing about us without us: Does action research in developmental disabilities research measure up? Journal of Policy and Practice in Intellectual Disabilities. Vol. 11 (2), 83-91.

Stobbe, M. (2011). Ugly past of U.S. human experiments: Tests including exposing mental patients and prisoners to infectious diseases. NBC News.com. www.nbcnews.com/id/41811750/ns/healthhealth_care/t/ugly-past-us-human-experiments-uncovered/\#.Xcsynm 5 Fyat.

The Arc. (n.d.). Our History. www.thearc.org/about-us/history/.

The World Bank. (2019). Disability inclusion. www.worldbank.org/en/topic/disability.

Trewin, S. (2018). AI faimess for people with disabilities: point of view. https://arxiv.org/abs/1811 $.10670 \mathrm{v} 1$.

United Nations. (1993). Standard Rules on the Equalization of Opportunities for Persons with Disabilities. www.un.org/development/desa/disabilities/standard-rules-on-the-equalization -of-opportunities-for-persons-with-disabilities.html. 
United Nations General Assembly. (2007). Convention on the Rights of Persons with Disabilities: resolution / adopted by the General Assembly, January 24, 2007, A/RES/61/ 106. www.refworld.org/docid/45f973632.html.

United Nations Department of Economic and Social Affairs Disability. (1981). The World Programme of Action Concerning Disabled Persons. www.un.org/development/desa/disabil ities/history-of-united-nations-and-persons-with-disabilities-the-world-programme-of-actionconcerning-disabled-persons.html.

United Nations Human Rights Office of the High Commissioner. (1966). International Covenant on Economic, Social and Cultural Rights. Available at www.ohchr.org/EN/ ProfessionalInterest/Pages/CESCR.aspx.

United Nations. Convention on the Rights of Persons with Disabilities and Its Optional Protocol (PPT) www.un.org/disabilities/documents/ppt/crpdbasics.ppt.

"What are some types of assistive devices and how are they used?" (n.d.). Eunice Kennedy Shriver National Institute of Child Health and Human Development. www.nichd.nih.gov /health/topics/rehabtech/conditioninfo/device.

"What are some types of rehabilitation technologies." (n.d.). Eunice Kennedy Shriver National Institute of Child Health and Human Development. www.nichd.nih.gov /health/topics/rehabtech/conditioninfo/device. 